\title{
Correction to: Body size and genetic variation in the White-tipped Plantcutter (Phytotoma rutila: Cotingidae) suggest ecological divergence across the Chaco-Andes dry forest belt
}

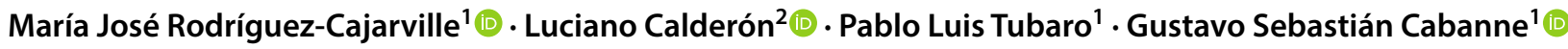

Published online: 17 October 2019

๑) Deutsche Ornithologen-Gesellschaft e.V. 2019

Correction to: Journal of Ornithology

https://doi.org/10.1007/s10336-019-01694-3

In the original publication of the article, there is a typo at the base text of Table 3 which is mentioned as "*** robust result when critical $c / h^{2}<2$ [following Brommer (2011)]". However, the correct text should be "** robust result when critical $c / h^{2}<0.2$ [following Brommer (2011)]".

The original article has been corrected.

The original article can be found online at https://doi.org/10.1007/ s10336-019-01694-3.

Gustavo Sebastián Cabanne gscabanne@yahoo.com

1 Museo Argentino de Ciencias Naturales "Bernardino Rivadavia”-CONICET, Avenida Ángel Gallardo 470, C1405DJR Buenos Aires, Argentina

2 Instituto de Biología Agrícola de Mendoza-CONICET-UNCUYO, Almirante Brown 500, CP 5505 Luján de Cuyo, Mendoza, Argentina 